\title{
Longdong Loess Mechanics Characteristics and Analysis based on Conventional Triaxial Test
}

\author{
Zhang Binwei1, 2, 3 Liu Wanfeng1, 3 Yang Xiao 4 Wang Yue4
}

(1. School of Civil Engineering, Longdong University, Qing yang, Gansu, 745000)

(2.School of Civil Engineering, Lanzhou Jiaotong University,Lanzhou,Gansu, 730070)

(3.Gansu universities "loess engineering properties and engineering application" provincial key Laboratory, Qingyang, Gansu, 745000)

(4. Bureau of housing and urban rural development,Huanxian County, Qingyang, Gansu, 745700)

Keywords: Loess landslides; Conventional triaxial test; Loess strength; Stress path

\begin{abstract}
TSZ-6A type strain control triaxial compression apparatus is applied for indoor test of some soil samples in Gansu Longdong (Qingyang) loess landslide, unconfined shear test of undisturbed soil samples, and the loading and unloading test of loess remodeling. The influences of different moisture content and confining pressure and the initial stress field on loess strength are considered respectively. Mechanical properties of loess in the state of loading and unloading state are compared and the corresponding q- $\varepsilon$ curves are drawn. The test shows that loess strength has a lot of structural characteristics, and loess structural damage has great impact on its strength. At the same time, the loess strength has important connection with its moisture content, stress state and stress path.
\end{abstract}

\section{INTRODUCTION}

Loess and loess-like soil cover more than $2.5 \%$ of the global continental area. The loess area in our country is about 64 square kilometers, and is the world's most widely distributed area, which mainly distributes in the northwest, followed by the northeast China plain and the southern region of the north. And the thickest loess strata are in northwest China, which is the most complete and continuous distribution with typical characteristics [1].

In recent years, with the strengthening of human economic and engineering activities, loess landslide disasters frequency shows an increasing trend, which poses a serious threat to people's life and property security and even causes mass death and casualty. Research on loess mechanical properties in landslide sliding zone is the basis to know loess landslide occurrence, development process and effective engineering design against sliding. Deep soil lager is widely distributed in Gansu Longdong (Qingyang) region and the loess deposits have experienced the effect of various geologic forces in the process of long geological history and formed various forms of ditch, trail, beam geology, and this also creates a large number of loess landslide geological disaster phenomena. In the process of loess deposits formation, due to different geological, climate and sedimentary environment, and so on, each region's loess sediments have their special engineering properties.

At present, Chinese scholars have had a lot of field investigation, in-situ tests and indoor tests in northern shan'xi, Guanzhong and Lanzhou and other regions, and gained rich research achievements. But the loess landslide sliding zone soil research in Longdong region of gansu province progresses slowly.

After Gansu province proposed "One Body Two Wings" development strategy, Longdong (Qingyang) oil, coal and other resources are developed and industrial construction is developed quickly. The basic mechanical properties study on loess landslide sliding zone soil is of great importance to Longdong region geological disaster prevention and the sustainable development of economy in Gansu province. 


\section{LOESS SLIDING ZONE SOIL TEST CONDITIONS}

\section{A. Loess landslide overview}

The loess landslide area is in the south of Red Almond Village located in Xifeng district of Qingyang city, Gansu province. As a result of the surface water erosion, the region has formed a variety of potential landslides land-form. Test sampling stage is just in melting period with more landslides. Landslide in sample point is shown in Figure 1.

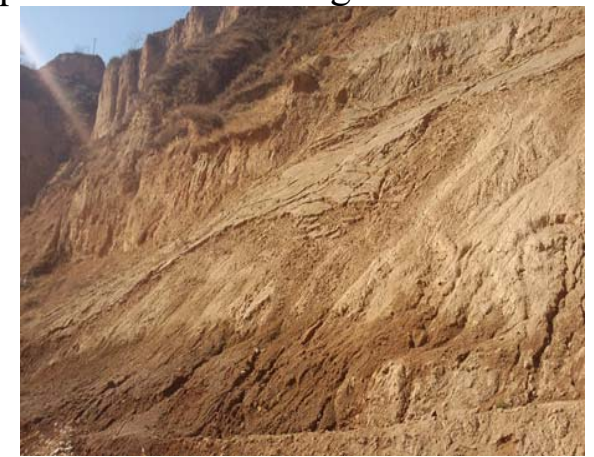

Figure 1 Landslide in sample point

In the landslide, take the soil sample at $2 \mathrm{~m}$ depth for experiments. The basic physical index of undisturbed soil samples is that density $\rho=1.85 \mathrm{~g} / \mathrm{cm} 3$, natural moisture content is $22.4 \%$, and the proportion is GS $=2.7$. The soil is hard plastic with bigger humidity and high strength.

B. Test equipment

This experiment adopts TSZ-6A type strain control triaxial compression apparatus for test. The instruments are designed and manufactured according to Soil Test Method Standard (GB/T50123-1999). Make three samples with each kind of specimen. Under poor conditions, take the average value and reduce the test error as far as possible to avoid larger discrete data.

$C$. The preparation and shear rate determination of the disturbed soil sample

In compaction device, make hierarchical compaction with three layers compaction. Each layer of soil samples is around a third, and each layer interface is debristled. Under the condition of free fall, each layer is compacted for 30 times. According to Geo-technical Test Method Standard GB/T50123-1999, remold soil samples and do tests without consolidation and draining, namely determine the soil sample's shear and cut rate as $0.12 \mathrm{~mm} / \mathrm{min}$ according to quick sheer mode, and dynamometer correction coefficient is $4.25 \mathrm{~N} / 0.01 \mathrm{~mm}$.

\section{THE UNCONFINED SHEAR TEST OF UNDISTURBED LOESS}

The unconfined compressive strength of the undisturbed loess, which is the specimen, under the condition of confining pressure is zero, and the limit intensity of resistance axial pressure is qu.

Test steps:

(1) Put the made soil sample on TSZ-6A type strain control triaxial compression apparatus, without confining pressure, apply principal stress until the specimen shear damage.

(2) Drawn Mohr - Coulomb strength envelope with the result of the experiment, and shear strength $\tau \mathrm{f}=\mathrm{Cu}=\mathrm{qu} / 2$.

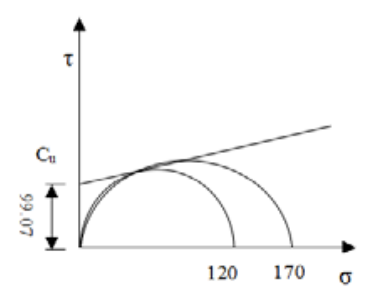

Figure 2 unconfined shear experiment strength envelop (UU experiment)

Figure 2 shows that in fact in unconfined experiment, soil's Mohr - Coulomb strength envelope is not horizontal, and has a certain angle. The angle just reflects undisturbed loess structural characteristics and friction characteristics between particles. Loess makes sedimentary formation 
under certain environment and historical conditions and has a certain particle characteristics, such as density, humidity and structure characteristics, and they all influence the engineering properties of loess [2].

It can be known from Figure 3 that the stress strain curve gets the soil's internal friction angle $\varphi \approx 0$ from ultimate stress circle through elastic stage to creep stage to $15 \%$ strain soft change state. The cohesion of soil is $\mathrm{Cu}=99 \mathrm{kpa}$. In engineering practice, non-consolidation and non-drainage shear strength (UU) is adopted to determine the short-term bearing capacity of soil and the stability of the soil.

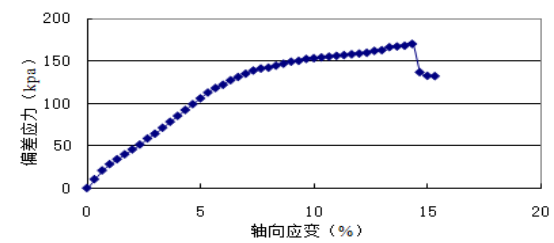

Figure 3 Unconfined shear test $q-\varepsilon 1$ curve

\section{THE LOADING DESTRUCTION TEST OF LOESS REMODELING}

To remodel the loess, in view of different initial stress condition, carry on preloading consolidation to simulate the normal consolidation condition of loess, and then, partial stress is applied to do the strength test of loess remodeling samples. The test conditions are shown in Table 1.

Figure 4 shows that with the increase of confining pressure, soil's stress strain curve it higher, which suggests that the destruction strength of the soil increases. The main reason is that with the increase of confining pressure, the space between soil particles is reduced with increasing compactness and enhanced soil ability to resist deformation. Remodeling loess samples with same water content $(15 \%, 18 \%$, and $24 \%)$ basically meet elastic-plastic characteristics. Under the condition of low confining pressure $(\sigma 3)$, soil samples show ideal elastic-plastic properties, and under the condition of high confining pressure $(\sigma 3)$, soil samples show some strain-hardening characteristics and its strength in larger; with the same moisture content, the greater the confining pressure $(\sigma 3)$, the greater the elastic deformation of soil mass and the higher the elastic limit. This test results is consistent with engineering practice. Under the condition of different water content in remodeling loess samples, the greater water content, the smaller is soil strength with greater ultimate strain of soil mass and greater shape. In the surrounding rock pressure $\left(\begin{array}{l}\sigma \\ \text { 3 }\end{array}\right)$ is equal, the smaller the water content, the higher and the soil strength. When the confining pressure is small, the ultimate strain of soil is small, and when the surrounding rock becomes larger, the ultimate strain of soil is also bigger.

The effect of confining pressure and moisture content on the soil strength is very big and occupies main factors, but by comparison, the moisture content is the main factors affecting mechanical properties of soil.

Figure 5 shows that with the increase of moisture content, shear indexes $\mathrm{C}$ and $\sigma$ values fall rapidly. This is consistent with the theory results, and cohesive force C's general trend is decreasing. With comparison, it is found that cohesive force $\mathrm{C}$ is affected by geologic time, particle morphology, and distribution and composition differences. Internal friction angle $\varphi$ is also in a downward trend before the moisture content gets to liquid limit with the increase of water content.

\begin{tabular}{|c|c|c|c|}
\hline \multirow{2}{*}{\multicolumn{2}{|c|}{ 侧压力系数 $(\lambda=0.4)$}} & \multicolumn{2}{|c|}{$\begin{array}{c}\text { 主应力 } \\
\text { (单位: } \mathrm{kpa})\end{array}$} \\
\cline { 2 - 4 } \multicolumn{2}{|c|}{} & $\sigma_{1}$ & $\sigma_{3}$ \\
\hline \multirow{2}{*}{$\begin{array}{c}\text { 模拟正常固结 } \\
\text { 状态 }\end{array}$} & I & 125 & 50 \\
\cline { 2 - 4 } & II & 250 & 100 \\
\cline { 2 - 4 } & III & 500 & 200 \\
\hline 含水量 $(\omega / \%)$ & 15 & 18 & 24 \\
\hline
\end{tabular}

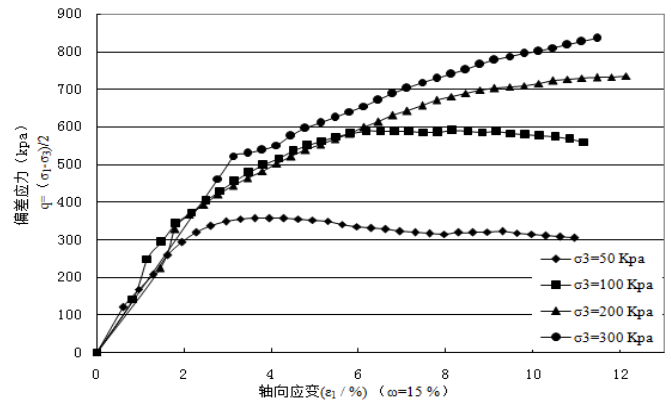


Table 1 Test related parameters

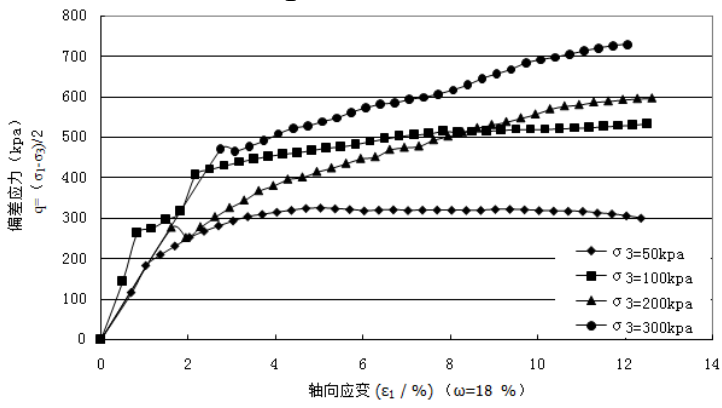

(b) The q- $\varepsilon 1$ curve when water content is $18 \%$ (a) The q- $\varepsilon 1$ curve when water content is $15 \%$

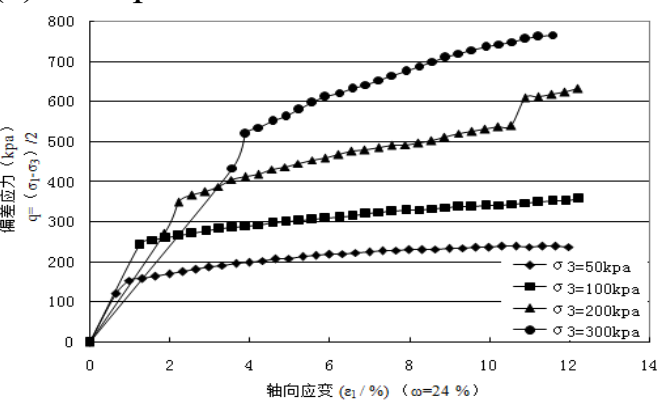

(c) The q- $\varepsilon 1$ curve when water content is $24 \%$ content $(\omega=15 \%$ omega, $\omega=15 \%, \omega=24 \%)$
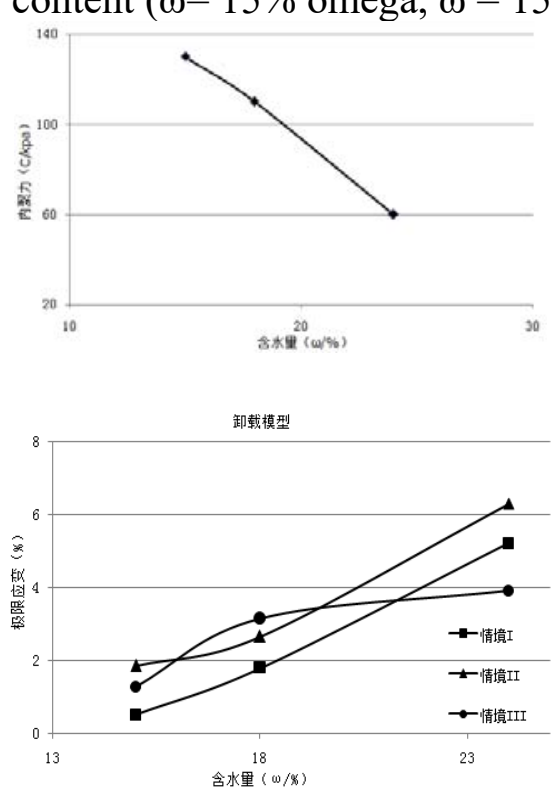

Figure 5 Ultimate strain comparison charts under different water content
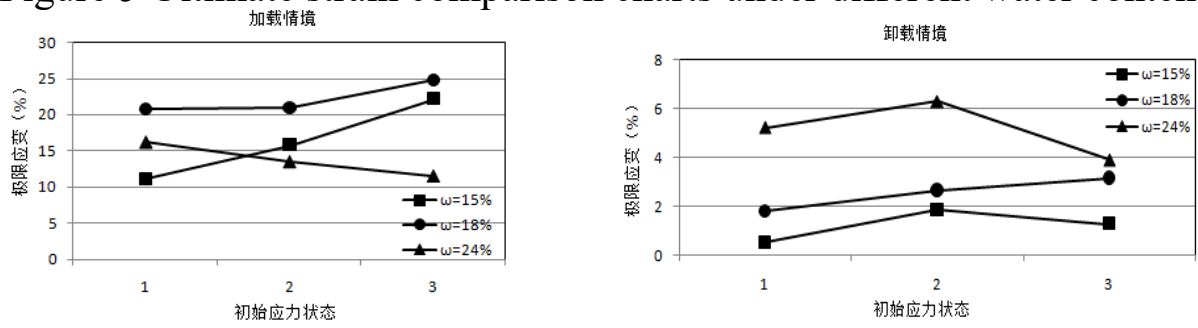

Figure 6 Ultimate strain comparison charts under different initial stress state

\begin{tabular}{|c|c|c|c|c|c|c|c|c|c|}
\hline \multirow[t]{4}{*}{$\underset{\infty}{\infty}$} & $\begin{array}{r}\omega \\
( \\
\%\end{array}$ & $\begin{array}{l}\quad \varepsilon_{\mathrm{u}}(\% \\
\text { (loadin } \\
\mathrm{g} \\
\text { model) }\end{array}$ & $\begin{array}{l}\varepsilon_{\mathrm{u}} \\
\text { (\%) } \\
\text { (unload } \\
\quad \text { ing } \\
\text { mode } \\
\text { 1) }\end{array}$ & $\begin{array}{l}\omega \\
\% \\
(\end{array}$ & $\begin{array}{l}\varepsilon_{\mathrm{u}(\%)}(\%) \\
\text { (loading } \\
\text { model) }\end{array}$ & $\begin{array}{l}\varepsilon_{\mathrm{u}} \\
(\%) \\
\text { (unload } \\
\text { ing } \\
\text { mode } \\
1)\end{array}$ & $\begin{array}{r}\omega \\
( \\
\%\end{array}$ & $\begin{array}{l}\quad \varepsilon_{\mathrm{u}} \\
(\%) \\
\text { (loadin } \\
\mathrm{g} \\
\text { model) }\end{array}$ & $\begin{array}{c}\varepsilon_{\mathrm{u}(\%)} \\
\text { (unloa } \\
\text { ding } \\
\text { mod } \\
\text { el) }\end{array}$ \\
\hline & 15 & 11.17 & 0.51 & 15 & 15.79 & 1.85 & 15 & 22.13 & 1.27 \\
\hline & 18 & 20.83 & 1.79 & 18 & 20.96 & 2.65 & 18 & 24.75 & 3.15 \\
\hline & 24 & 16.25 & 5.21 & 24 & 13.56 & 6.29 & 24 & 11.58 & 3.90 \\
\hline $\begin{array}{l}\text { situatio } \\
\mathrm{n}\end{array}$ & \multicolumn{3}{|c|}{$\begin{array}{c}\mathrm{I}: \quad \sigma_{1}=250 \mathrm{Kap} \\
\sigma_{3}=100 \mathrm{Kap}\end{array}$} & \multicolumn{3}{|c|}{$\begin{array}{c}\text { II: } \quad \sigma 1=500 \mathrm{Kap} \\
\sigma 3=200 \mathrm{Kap}\end{array}$} & \multicolumn{3}{|c|}{$\begin{array}{l}\text { III: } \sigma 1=750 \mathrm{Kap}, \\
\sigma 3=300 \mathrm{Kap}\end{array}$} \\
\hline
\end{tabular}

Table 2 Ultimate strain comparison table under loading and unloading conditions 


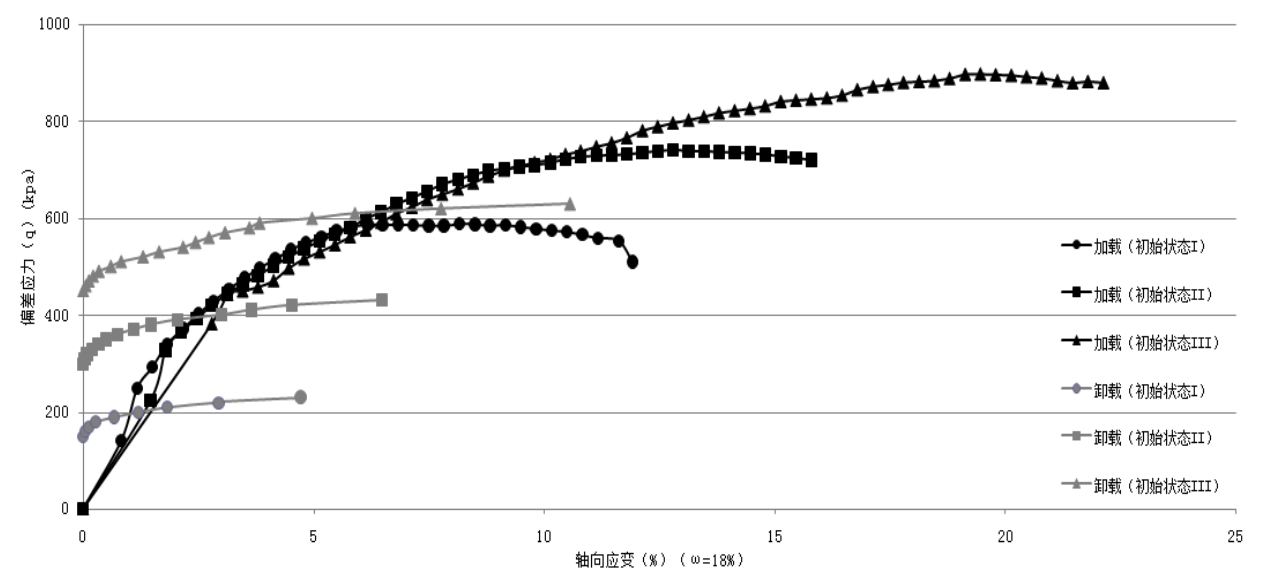

Figure 7 Loading and unloading q- $\varepsilon 1$ comparison chart under different initial stress state

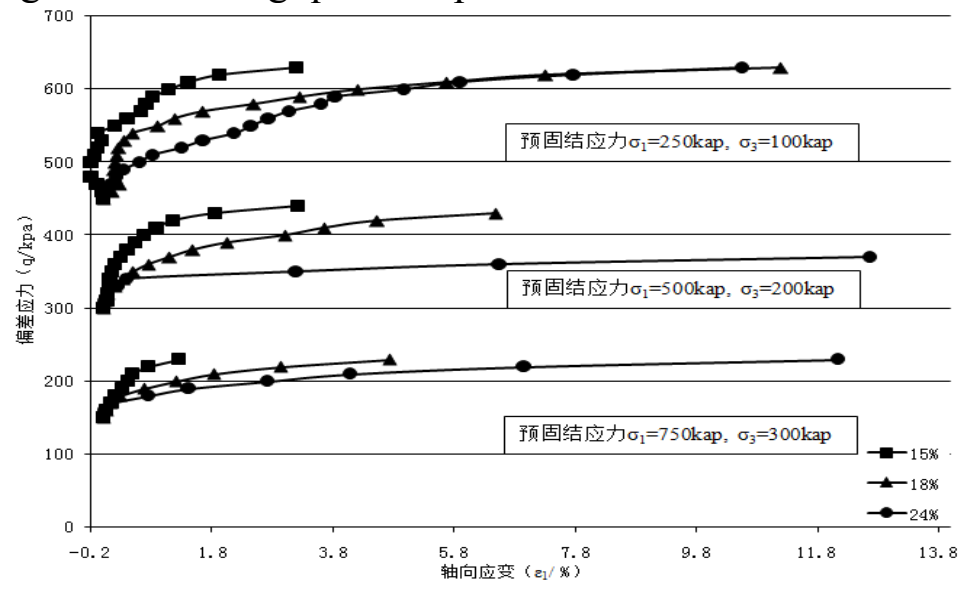

\section{LOESS LOADING - UNLOADING DESTRUCTIVE TEST COMPARISON}

In order to facilitate the comparison of the loading and unloading test of loess remodeling, the remodeled loess is given specific initial stress state, and set up three kinds of test scenarios, and loading and unloading experiments are conducted from the given initial stress state. The remodeled loess sample's loading and unloading test comparison is shown in Table 2.

Figure 6 shows that (1) in loading state, when the water content is less than $18 \%$, under the same moisture content, the greater the confining pressure, the greater the ultimate strain; And with the increase of water content, ultimate strain is gradually rising. But when moisture content is more than $18 \%$, under the same moisture content, the greater confining pressure, the smaller the pole limit strain.

With the increase of water content, ultimate strain decreases gradually, which shows that in loading state, water content has a critical value, and the critical value directly determines the deformation characteristics of the soil mass loading. (2) In unloading state, when the confining pressure is less than $300 \mathrm{kpa}$, with the increase of water content, ultimate strain also gradually increases. With the same water content, the greater confining pressure, the ultimate strain also is larger; but when the confining pressure is greater than $300 \mathrm{kpa}$, with the increase of water content, ultimate strain also increases overall, but when the moisture content is more than $18 \%$, the greater confining pressure, its ultimate strain reduces. The specification is that under unloading condition, there exists a critical confining pressure, and the critical value directly determines the unloading deformation characteristics of soil.

Figure 7 shows that (1) in loading state, when the water content is less than $18 \%$, with the increase of initial stress field, ultimate strain also gradually increases. When the moisture content is more than $18 \%$, the ultimate strain decreases while initial stress field increases. (2) In unloading state, there exists a critical stress state. In a low stress state, the greater the confining pressure, the greater the ultimate strain. In high stress state, the greater confining pressure, the ultimate strain 
decreases. This also shows that with the increase of water content, ultimate strain increases generally. This rule has nothing to do with the initial state of stress field. (3) The ultimate strain of loading mode is ten times larger than that of unloading way. The general trend is that the greater pre-compressed state, the relatively larger is ultimate strain. Complex linear rheological deformation calculation provides theoretical basis for engineering practice.

Figure 8 shows that load state specimen has great ultimate strain and shows larger strain-hardening and softening properties, and unload condition specimen has small ultimate strain and has a certain brittle characteristics. Either for loading or unloading state, the greater initial consolidation stress, the greater the samples' ultimate load, and the greater the loess strength. This reflects that loess foundation and loess foundation pit have different deformation characteristics. Similar projects in deep loess areas must pay attention to loess deformation difference of loading and unloading. Deformation and strength properties of soil should have stress path effect, regardless of unrecoverable volume strain or irreversible shear strain has very strong stress path correlation [3].

Figure 9 shows that loess samples' unloading state has the following characteristics: (1) when the water content is the same, the initial consolidation stress of soil samples is greater, and the deformation characteristics are better with greater ultimate strain and greater loess strength. This is due to the consolidation stress increases the cementation and friction effect of loess, and loess particles have mutual attraction between molecules. The cementation of package soil particles' salt contents, such as $\mathrm{CaCO} 3$ and $\mathrm{MgCO} 3$ and $\mathrm{CaSO} 4, \mathrm{NaCO} 3$ and $\mathrm{NaCl}$ plays an important role in loess strength. (2) When the initial consolidation stress is the same, the greater moisture content, the better plastic character loess samples and the greater the ultimate strain. However, the ultimate strength decreases instead, which indicates that for normal consolidated loess field, the greater water content, the bigger rheological behavior will happen in excavations, and under low loading condition, a lot of unloading deformation may occur. (3) When loess samples have low moisture content and larger preloading consolidation stress, the unloading specimen shows a certain unloading rebound phenomenon, which is due to the loess samples' resilient modulus elasticity is larger. For deep loess ground with bigger consolidation stress, we need to pay attention to the excavation unloading rebound deformation. By Figure 8 and Figure 9, the axial displacement increase of loess, with the decrease of confining pressure, in initial stage is not apparent and shows linear elastic change but when gets to failure loading, samples' axial deformation rapidly grows until damages [4].

\section{CONCLUSION}

This paper makes undisturbed soil and remolded soil triaxial test with Gansu Longdong (Qingyang) loess landslide soil samples with the consideration of different water content, confining pressure, different initial consolidation stress state, loading and unloading effect on loess strength, and the experimental data show that:

(1) Loess has a lot of constitutive property, and loess structural damage influences greatly its strength. Remodeled loess specimens under low confining pressure conditions show ideal elastic-plastic properties, and under the condition of high confining pressure, soil samples show some strain-hardening characteristics;

(2) With the same moisture content, the greater the confining pressure, the greater the elastic deformation of soil mass with higher elastic limit. The loess samples with low moisture content and larger preloading consolidation stress, the unloading specimen show a certain unloading rebound phenomenon. This is due to loess samples' resilient elasticity modulus is larger, and for deep loess ground with bigger consolidation stress, pays attention to excavation unloading rebound deformation.

(3) The ultimate strain of loading way is ten times larger than that of unloading way and the general trend is that the greater pre-compressed state, the relatively larger ultimate strain. For unloading state, there exists a critical stress state. In low stress state, the greater the confining pressure, the greater the ultimate strain. In high stress state, the greater the confining pressure, the 
ultimate strain decreases.

(4) The loading and unloading tests of the loess show that loess foundation and loess foundation pit have different deformation characteristics. The similar projects in deep loess areas must pay attention to loess loading and unloading deformation differences.

\section{REFERENCES}

[1] Xing Yichuan. Development and outlook of loess mechanics study [J]. Journal of Hydroelectric Power Journal, 2000, (4) : 54-63.

[2] Shao Shengjun, Tao $\mathrm{Hu}, \mathrm{Xu}$ Ping. Loess structural mechanics characteristic research and application discussion [J]. Rock and Soil Mechanics, 2011, 32 (2) : 42-50.

[3] Peng Fangle, Li Fulin, Bai Xiaoyu. Sand play sticky plastic constitutive model considering stress path and loading rate effect [J]. Journal of Rock Mechanics and Engineering, 2009, 28 (5) : 929-938.

[4] Ye Chaoliang, Zhu Yongquan, Liu Yaojun. The experimental study of undisturbed loess anisotropy and unloading deformation characteristics [J]. China Railway Science, 2014, 35 (6) : $1-5$. 